\title{
Accuracy of dobutamine stress echocardiography for the diagnosis of coronary artery stenosis in patients with myocardial infarction: the impact of extent and severity of left ventricular dysfunction
}

Abdou Elhendy, Ron T van Domburg, Jos R T C Roelandt, Marcel L Geleijnse, Jan H Cornel, Galal M El-Said, Paolo M Fioretti

\begin{abstract}
Objectives-To assess the value of dobutamine stress echocardiography (DSE) in the prediction of the extent and location of coronary artery stenosis in symptomatic patients with old myocardial infarction and to study the impact of the severity of resting wall motion abnormalities (WMA) on the diagnostic accuracy of the test.

Patients-One hundred and thirty two symptomatic patients with old myocardial infarction.

Methods-DSE (up to $40 \mu \mathrm{g} / \mathrm{kg} / \mathrm{min}$, with atropine up to $1 \mathrm{mg}$ ) was performed in all patients. Ischaemia was defined as new or worsened WMA. For each coronary artery, regional wall motion in the corresponding territory was classified as normal, mildly, moderately, or severely impaired according to the wall motion score index. Significant coronary stenosis was defined as $\geqslant \mathbf{5 0 \%}$ diameter stenosis.
\end{abstract}

Results-A positive DSE for ischaemia occurred in 87 of 111 patients with and three of 21 patients without coronary artery stenosis (sensitivity $=78 \%$; CI 71 to 86 , specificity $=86 \%$; CI 79 to 92 , accuracy $=80 \%$; CI 73 to 87 ). The accuracy for the diagnosis of individual coronary stenosis was $69 \%$ in the presence of normal wall motion and $74 \%, 74 \%$, and $61 \%$ respectively when there was mild, moderate, and severe WMA in the corresponding territories $(P=N S)$. The sensitivity was higher in presence of mild or moderate WMA (73\%) than with normal wall motion (53\%) or severe WMA $(56 \%, P<0.05$ in both). In territories subtended by a stenotic artery, the regional wall motion score index was not different with or without ischaemia. Conclusion-DSE had a good overall accuracy for the diagnosis of coronary artery stenosis in symptomatic patients with old myocardial infarction. The presence of resting WMA did not limit DSE as a method of eliciting myocardial ischaemia and diagnosing significant coronary artery stenosis in patients with old myocardial infarctions.

(Heart 1996;76:123-128)

Keywords: coronary artery disease; myocardial infarction; dobutamine stress echocardiography; ischaemia.

The presence of residual ischaemic myo- cardium within a prior infarct zone at exercise myocardial perfusion scintigraphy identifies patients at high risk late after acute myocardial infarction. ${ }^{1}$ Dobutamine stress echocardiography (DSE) is increasingly used for the diagnosis and functional evaluation of coronary artery disease in patients with limited exercise capacity. ${ }^{2-6}$ However, few studies have been designed to assess the role of this technique in the evaluation of the extent and location of coronary artery disease in patients with myocardial infarction ${ }^{2-4}$ and most of them were restricted to asymptomatic populations early after acute myocardial infarction. ${ }^{23}$ The value of DSE has not been assessed in a homogeneous population with old myocardial infarction and suspected myocardial ischaemia, who represent a substantial proportion of patients referred for the functional assessment of coronary artery disease. Furthermore, the influence of the extent and severity of resting wall motion abnormalities (WMA) on the accuracy of DSE for the diagnosis of significant coronary artery stenosis on the basis of inducible ischaemia has not been assessed. This is important, because the echocardiographic diagnosis of myocardial ischaemia relies upon the occurrence of new or worsening WMA, ${ }^{46}$ which may be difficult to elicit, in presence of severe resting WMA. ${ }^{5}$ In some studies, the presence of baseline WMA was regarded as diagnostic of significant coronary artery stenosis. ${ }^{67}$ This approach does not disclose the relation between the patients' symptoms and myocardial ischaemia and may be confounding after thrombolytic therapy or revascularisation of the infarct-related artery. Therefore, the aim of this study was to assess the accuracy of DSE for the diagnosis of coronary artery stenosis on basis of inducible ischaemia and to find whether baseline left ventricular dysfunction influences the accuracy of the test for the diagnosis of individual coronary artery stenosis in patients with old myocardial infarction.

\section{Patients and methods}

PATIENT SELECTION

We studied 132 patients with chest pain who were unable to perform an adequate exercise test and who were referred to our imaging laboratory for evaluation of myocardial ischaemia. Chest pain was classified as typical angina in 62 and atypical in 70 patients. All patients fulfilled the following criteria: (a) previous myocardial infarction $>$ three months; $(b)$ the presence of 
WMA at rest; and (c) absence of severe heart failure, severe valvar heart disease, hypertension, hypotension or a history of sustained ventricular tachyarrhythmias. All patients gave an informed consent to undergo DSE. Mean (SD) age was 60 (9) years. There were $101 \mathrm{men}$ and 31 women. Ninety patients $(68 \%)$ were receiving oral nitrates and/or calcium antagonists and $38(29 \%)$ were receiving $\beta$ blockers on the day of the test. $\mathrm{Q}$ waves were present in 88 patients $(67 \%)$, and were present in the anterior (or anterolateral) leads in 40 patients, inferior (or inferolateral) leads in 31 patients, and in both in 17 patients. The accuracy of DSE for the diagnosis of remote coronary artery stenosis in the study population was compared with a control group of 25 asymptomatic patients with old myocardial infarction (mean (SD) age 58 (10) years; 19 men).

\section{DOBUTAMINE STRESS ECHOCARDIOGRAPHY}

Dobutamine was infused through an antecubital vein starting at a dose of 5 followed by $10 \mu \mathrm{g} / \mathrm{kg} / \mathrm{min}$ (three minutes stages), increasing by $10 \mu \mathrm{g} / \mathrm{kg} / \mathrm{min}$ every three minutes to a maximum of $40 \mu \mathrm{g} / \mathrm{kg} / \mathrm{min}$. Atropine (up to $1 \mathrm{mg}$ ) was given in patients not achieving $85 \%$ of their age predicted maximal heart rate. ${ }^{8}$ The electrocardiogram was monitored throughout dobutamine infusion and was recorded each minute. Cuff blood pressure was measured every three minutes. The test was interrupted if severe chest pain, ST segment depression $>2$ $\mathrm{mm}$, significant ventricular or supraventricular arrhythmia, or a fall in systolic blood pressure of $>40 \mathrm{~mm} \mathrm{Hg}$ occurred during the test. Echocardiographic images were acquired at rest and during stress and recovery. Images were recorded on video tapes and were also digitised on optical disk and displayed side by side in a quad-screen format (Vingmed CFM 800 ) to facilitate the comparison of rest and stress images. The left ventricular wall was divided into 16 segments and scored using a 4point scale, where $1=$ normal, $2=$ hypokinesis, 3 = akinesis, $4=$ dyskinesis. ${ }^{4}$ The images were interpreted by two experienced observers without the knowledge of the patients' clinical or angiographic data. When they disagreed, a third reviewer reviewed the images and a majority decision was achieved. In our laboratory, the inter and intra observer agreements for stress echocardiography are $91 \%$ and $92 \%$ respectively. The wall motion score index (WMSI) was derived by dividing the sum of the scores of the 16 segments by 16 . For each vascular territory, regional WMSI was derived by adding the score for segments in the related territory and dividing the sum by the number of segments. Three grades of regional dysfunction were defined by the WMSI: (a) mild $(<1 \cdot 7),(b)$ moderate $(1 \cdot 7-2 \cdot 3)$, and $(c)$ severe $(>2 \cdot 3)$. The dyssynergy index was derived by dividing the number of dyssynergic segments by the total number of segments in each vascular territory. Similarly, the akinesis-dyskinesis index was derived by dividing the number of akinetic and dyskinetic segments by the total number of segments in the same territory. Ischaemia was defined as new or worsened
WMA. As we have previously concluded, ${ }^{9}$ ischaemia was not considered when akinetic segments at rest became dyskinetic during stress unless they improved with low dose dobutamine (5-10 $\mu \mathrm{g} / \mathrm{kg} / \mathrm{min})$. Peri-infarction ischaemia was regarded as ischaemia occurring in the distribution of infarct related artery. Resting WMAs were used to localise the infarction in absence of $Q$ waves.

\section{CORONARY ANGIOGRAPHY}

Coronary angiography was performed, using the Judkins technique, within three months in all patients. Significant coronary artery disease was defined as a diameter stenosis $\geqslant 50 \%$ in $\geqslant 1$ major epicardial arteries measured as described previously from our centre. ${ }^{10}$ Ischaemia at DSE was correlated with the presence or absence of significant coronary stenosis. Coronary arteries were assigned to particular myocardial segments at echocardiography as previously described. ${ }^{11}$

\section{STATISTICAL ANALYSIS}

Unless specified, data are presented as mean values and standard deviation (SD). The chi squared test and Fisher's exact test were used to compare differences between proportions. Student's $t$ test was used for analysis of continuous data. $P<0.05$ was regarded as statistically significant. Sensitivity, specificity, predictive value, and accuracy were derived according to standard definition and presented with their corresponding $95 \%$ confidence interval (CI).

\section{Results}

\section{DOBUTAMINE STRESS TEST}

Heart rate increased from 70 (13) at rest to 136 (16) beats $/ \mathrm{min}$ at peak stress $(P<0.0001)$ and rate-pressure product from 9003 (2563) to 17707 (9204) $(\mathrm{P}<0.0001)$ whereas systolic blood pressure did not change significantly (128 (19) at rest $v 131$ (28) $\mathrm{mm} \mathrm{Hg}$ at peak stress). Angina occurred in $62(47 \%)$ patients, ST segment depression in $46(35 \%)$, and ST segment elevation in $40(30 \%)$ patients (with or without concomitant ST segment depression). In $28(21 \%)$ patients the test was interrupted before the maximal dose or the target heart rate was reached, because of angina (13 patients), ST segment depression (three patients), hypotension (10 patients), and significant tachyarrhythmias (two patients).

\section{CORONARY ANGIOGRAPHY}

Significant coronary artery stenosis was detected in 111 patients (84\%). Thirty two patients $(24 \%)$ had single vessel disease, 45 (34\%) had two vessel disease, and $34(26 \%)$ had three vessel disease. Twenty one patients had normal coronary arteries or $<50 \%$ lesions. In coronary arteries with significant stenosis, the mean $\%$ diameter stenosis was significantly higher in arteries with WMA in the corresponding territories than in those without $(P<0.01$ in the LAD and RCA and P $<0.05$ in LCx). The mean number of stenotic coronary arteries was $1.9(0.8)$ in patients with mild WMA and 
Table 1 Accuracy of dobutamine stress echocardiography for the diagnosis of significant $L A D$ stenosis on basis of inducible ischaemia in the presence or absence of regional wall motion abnormalities in the corresponding territories

\begin{tabular}{|c|c|c|c|}
\hline & Sensitivity & Specificity & Accuracy \\
\hline \multicolumn{4}{|l|}{ Overall: } \\
\hline$\%(\mathrm{CI})$ & 59 (51 to 67$)$ & $82(75$ to 88$)$ & 67 (59 to 76$)$ \\
\hline Number & $49 / 83$ & $40 / 49$ & $89 / 132$ \\
\hline \multicolumn{4}{|l|}{ Normal wall motion: } \\
\hline $\begin{array}{l}\%(\mathrm{CI}) \\
\text { Number }\end{array}$ & $\begin{array}{l}50(33 \text { to } 67) \\
7 / 14\end{array}$ & $\begin{array}{l}83(70 \text { to } 96) \\
15 / 18\end{array}$ & $\begin{array}{l}69(53 \text { to } 85) \\
22 / 32\end{array}$ \\
\hline \multicolumn{4}{|l|}{$\begin{array}{l}\text { Number } \\
\text { Mild WMA: }\end{array}$} \\
\hline $\begin{array}{l}\%(\mathrm{CI}) \\
\text { Number }\end{array}$ & $71(56$ to 87$)$ & $85(72$ to 97$)$ & $\begin{array}{l}76(62 \text { to } 91) \\
26 / 34\end{array}$ \\
\hline \multicolumn{4}{|l|}{ Moderate WMA: } \\
\hline $\begin{array}{l}\%(\mathrm{CI}) \\
\text { Number }\end{array}$ & $\begin{array}{l}55(36 \text { to } 74) \\
11 / 20\end{array}$ & $\begin{array}{l}75(59 \text { to } 91) \\
6 / 8\end{array}$ & $\begin{array}{l}61(43 \text { to } 79) \\
17 / 28\end{array}$ \\
\hline \multicolumn{4}{|l|}{ Severe WMA: } \\
\hline $\begin{array}{l}\%(\mathrm{CI}) \\
\text { Number }\end{array}$ & $\begin{array}{l}57(41 \text { to } 73) \\
16 / 28\end{array}$ & $\begin{array}{l}80(67 \text { to } 83) \\
8 / 10\end{array}$ & $\begin{array}{l}63(48 \text { to } 78) \\
24 / 38\end{array}$ \\
\hline
\end{tabular}

CI, 95\% confidence interval; WMA, wall motion abnormalities; number, number of patients.

Table 2 Accuracy of dobutamine stress echocardiography for the diagnosis of significant $L C x$ stenosis on basis of inducible ischaemia in the presence or absence of regional wall motion abnormalities in the corresponding territories

\begin{tabular}{|c|c|c|c|}
\hline & Sensitivity & Specificity & Accuracy \\
\hline \multicolumn{4}{|l|}{ Overall: } \\
\hline $\begin{array}{l}\%(\mathrm{CI}) \\
\text { Number }\end{array}$ & $\begin{array}{l}53(45 \text { to } 62) \\
34 / 64\end{array}$ & $\begin{array}{l}82(76 \text { to } 89) \\
56 / 68\end{array}$ & $\begin{array}{l}68(60 \text { to } 76) \\
90 / 132\end{array}$ \\
\hline \multicolumn{4}{|l|}{ Normal wall motion: } \\
\hline $\begin{array}{l}\%(\mathrm{CI}) \\
\text { Number }\end{array}$ & $\begin{array}{l}39(27 \text { to } 51) \\
9 / 23\end{array}$ & $\begin{array}{l}90(82 \text { to } 97) \\
35 / 39\end{array}$ & $\begin{array}{l}71(60 \text { to } 82) \\
44 / 62\end{array}$ \\
\hline \multicolumn{4}{|l|}{ Mild WMA: } \\
\hline $\begin{array}{l}\%(\mathrm{CI}) \\
\text { Number }\end{array}$ & $\begin{array}{l}47(28 \text { to } 66) \\
8 / 17\end{array}$ & $\begin{array}{l}78(62 \text { to } 94) \\
7 / 9\end{array}$ & $\begin{array}{l}58(39 \text { to } 77) \\
15 / 26\end{array}$ \\
\hline \multicolumn{4}{|l|}{ Moderate WMA: } \\
\hline $\begin{array}{l}\%(\mathrm{CI}) \\
\text { Number }\end{array}$ & $\begin{array}{l}73(57 \text { to } 89) \\
11 / 15\end{array}$ & $\begin{array}{l}71(55 \text { to } 88) \\
10 / 14\end{array}$ & $\begin{array}{l}72(56 \text { to } 89) \\
21 / 29\end{array}$ \\
\hline \multicolumn{4}{|l|}{ Severe WMA: } \\
\hline $\begin{array}{l}\%(\mathrm{CI}) \\
\text { Number }\end{array}$ & $\begin{array}{l}67(43 \text { to } 91) \\
6 / 9\end{array}$ & $\begin{array}{l}67(43 \text { to } 91) \\
4 / 6\end{array}$ & $\begin{array}{l}67(43 \text { to } 91) \\
10 / 15\end{array}$ \\
\hline
\end{tabular}

CI, 95\% confidence interval; WMA, wall motion abnormalities; number, number of patients.

Table 3 Accuracy of dobutamine stress echocardiography for the diagnosis of significant $R C A$ stenosis on basis of inducible ischaemia in the presence or absence of regional wall motion abnormalities in the corresponding territories

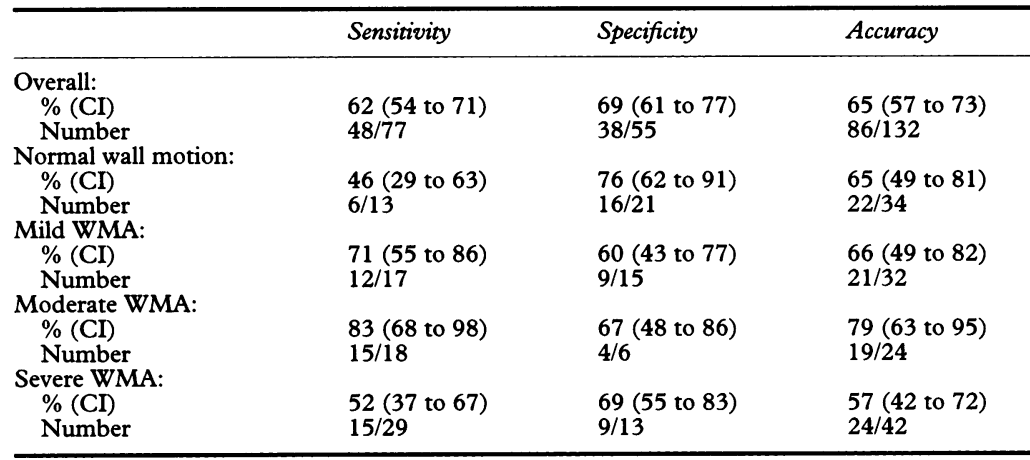

CI, $95 \%$ confidence interval; WMA, wall motion abnormalities; number, number of patients.

Table 4 Accuracy of dobutamine stress echocardiography for the diagnosis of significant RCA and/or LCX stenosis on basis of inducible ischaemia in the presence or absence of regional wall motion abnormalities in the corresponding territories

\begin{tabular}{llll}
\hline & Sensitivity & Specificity & Accuracy \\
\hline $\begin{array}{lll}\text { Overall: } \\
\text { \% (CI) }\end{array}$ & $72(64$ to 79$)$ & $76(68$ to 83$)$ & $73(65$ to 80$)$ \\
$\begin{array}{l}\text { Number } \\
\text { Normal wall motion: }\end{array}$ & $68 / 95$ & $28 / 37$ & $96 / 132$ \\
$\begin{array}{l}\text { \% (CI) } \\
\text { Number }\end{array}$ & $56(38$ to 74$)$ & $86(73$ to 98$)$ & $70(54$ to 86$)$ \\
$\begin{array}{l}\text { Mild WMA: } \\
\text { \% (CI) }\end{array}$ & $9 / 16$ & $12 / 14$ & $21 / 30$ \\
$\quad$ Number & $73(60$ to 87$)$ & $67(52$ to 81$)$ & $71(58$ to 85$)$ \\
$\begin{array}{l}\text { Moderate WMA: } \\
\text { \% (CI) }\end{array}$ & $22 / 30$ & $8 / 12$ & $30 / 42$ \\
Number & $85(74$ to 96$)$ & $71(58$ to 85$)$ & $83(71$ to 94$)$ \\
Severe WMA: & $29 / 34$ & $5 / 7$ & $34 / 41$ \\
\% (CI) & $53(31$ to 76$)$ & $75(55$ to 95$)$ & $58(36$ to 80$)$ \\
Number & $8 / 15$ & $3 / 4$ & $11 / 19$ \\
\hline
\end{tabular}

CI, 95\% confidence interval; WMA, wall motion abnormalities; number, number of patients.
$2 \cdot 1(0 \cdot 8)$ with moderate or severe WMA $(P=$ NS).

STRESS ECHOCARDIOGRAPHY

WMSI increased significantly from baseline (mean $1.71(0.46)$ ) to peak stress (mean 1.90 $(0.52), \quad P<0.001)$. A positive DSE for ischaemia occurred in 87 of 111 patients with significant coronary artery stenosis and in three of the 21 patients without significant coronary artery disease; two of them had lesions between 40 and $45 \%$ in the related artery (sensitivity = $78 \%$; CI 71 to 86 , specificity $=86 \%$; CI 79 to 92, positive predictive value $=97 \%$; CI 93 to 100 , negative predictive value $=43 \%$; $\mathrm{CI}=$ 34 to 51 ; accuracy $=80 \%$; CI 73 to 87 ). The sensitivity was $66 \%$ in patients with single vessel disease, $82 \%$ in two vessel disease, and $85 \%$ in three vessel disease. The sensitivity was higher in patients with multivessel than with single vessel disease $(84 \%$ v $66 \%, \mathrm{P}<0.05)$. An ischaemic pattern in two different vascular territories, suggestive of multivessel involvement occurred in 37 of 79 patients with multivessel disease and in six of 53 patients with single vessel or without coronary artery stenosis (sensitivity $=47 \%$; CI 38 to 55 , specificity $=$ $89 \%$; CI 83 to 94 , positive predictive value $=$ $86 \%$; CI 80 to 92 , negative predictive value $=$ $53 \% ; \mathrm{CI}=44$ to 61 ; accuracy $=64 \%$; CI 55 to 72$)$. Sensitivity was $73 \%(43 / 58)$ in patients with mild, $87 \%$ (34/39) with moderate, and $75 \%(10 / 14)$ with severe WMA ( $P=N S)$. A positive DSE (peri-infarction ischaemia) occurred in 74 of 98 patients with and in five of 34 patients without significant infarct-related artery stenosis (sensitivity $=76 \%$; CI 68 to 83 , specificity $=85 \%$; CI 79 to 92 , positive predictive value $=94 \%$; CI 89 to 98 , negative predictive value $=55 \%$; CI 46 to 63 , accuracy $=$ $78 \%$; CI 71 to 85 . A positive DSE (remote ischaemia) was detected in 54 of 74 patients with and in five of 41 patients without remote coronary artery stenosis (after exclusion of 17 patients with extensive infarction and WMA involving the three vascular territories) (sensitivity $=73 \%$; CI 69 to 81 , specificity $=88 \%$; CI 82 to 94 , positive predictive value $=92 \%$; CI 86 to 97 , negative predictive value $=64 \%$; CI 55 to 73 , accuracy $=78 \%$; CI 71 to 86 ). In the 25 asymptomatic patients who served as a control group, a positive DSE (remote ischaemia) was detected in seven of 11 patients with and in two of 14 patients without remote coronary artery stenosis (sensitivity $=64 \%$; CI 45 to 83 , specificity $=86 \%$; CI 72 to 99 , positive predictive value $=78 \%$; CI 61 to 94 , negative predictive value $=75 \%$; CI 58 to 92 , accuracy $=78 \% ; \mathrm{CI}=71$ to $86, \quad \mathrm{P}=\mathrm{NS}$ $v$ the study group).

DETECTION OF INDIVIDUAL CORONARY ARTERY STENOSIS

The sensitivity, specificity, and accuracy of DSE for the detection of individual coronary artery stenosis are shown in tables 1-3. Sensitivity was not different in the three vascular territories. There was a trend to a lower specificity in the RCA compared with other territories. Because some of the false positive results 
Table 5 Accuracy of dobutamine stress echocardiography for the diagnosis of individual coronary artery stenosis in the presence or absence of regional wall motion abnormalities in the corresponding territories, derived by adding scores for LAD to those of the combined $R C A$ and $L C x$ territories

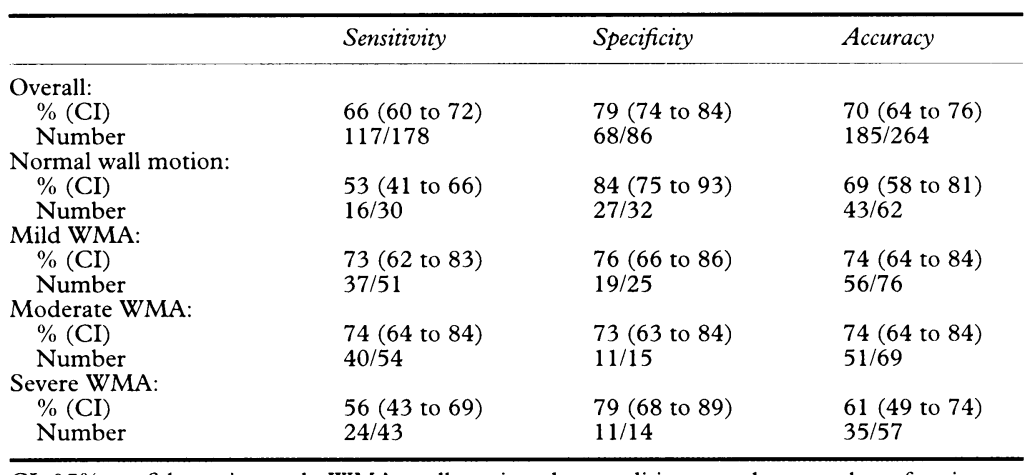

CI, $95 \%$ confidence interval; WMA, wall motion abnormalities; number, number of patients.

in the inferior wall may be attributed to LCx disease, the vascular territories of RCA and LCx were grouped and abnormalities were assigned to a disease in either of them (table 4). This approach increased the specificity of the RCA from $69 \%$ to $76 \%$, meanwhile the specificity of the LCx decreased from $82 \%$ to $76 \%$. The overall accuracy for detection of individual coronary artery stenosis was derived by adding

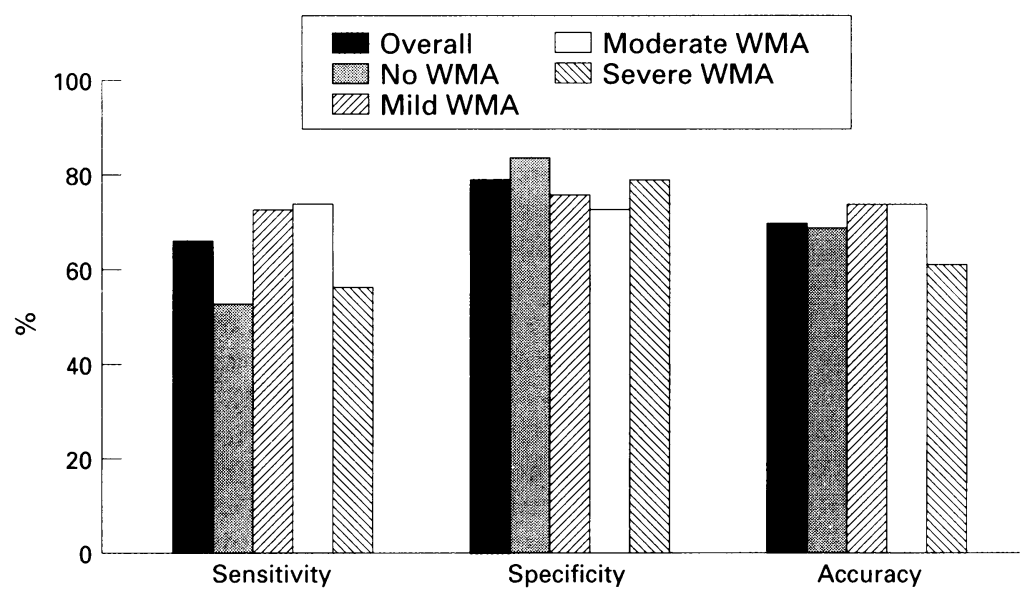

Figure 1 Sensitivity, specificity, and accuracy of dobutamine stress echocardiography for the diagnosis of individual coronary stenosis in vascular territories with normal wall motion and mild, moderate, and severe wall motion abnormalities (WMA).

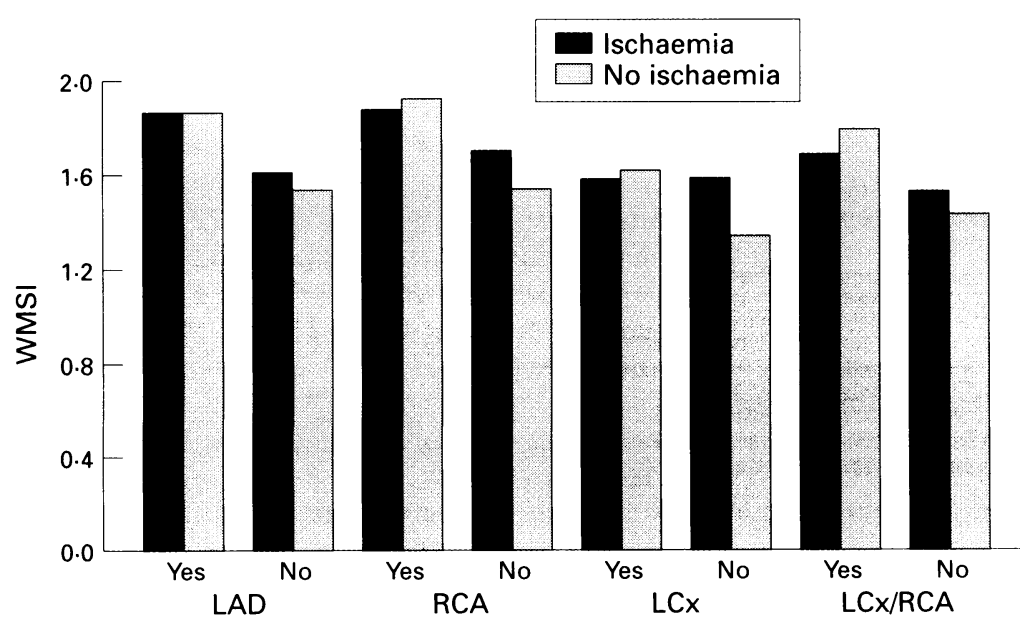

Figure 2 Regional wall motion score index (WMSI) in individual vascular territories with or without significant stenosis of the related artery and in the presence or absence of with or without significant stenosis of the related artery and in the
regional ischaemia during dobutamine stress echocardiography. the accuracy for LAD to the accuracy in the combined RCA and LCx segment (table 5). Accuracy was not significantly different in presence or absence of baseline WMA and with various grades of regional dyssynergy in the related vascular territories (fig 1). However, the sensitivity in territories with mild and moderate WMA (added together) was higher than in territories with severe WMA $(73 \%$ v 56\%, $\mathrm{P}<0.05)$ and in those with normal resting wall motion $(73 \% v 53 \%, P<0.05)$. In individual vascular territories subtended by a stenotic coronary artery there was no significant difference in baseline regional WMSI (fig 2), dyssynergy index (fig 3), akinesis-dyskinesis index (fig 4 ), both in the presence (true positive) or absence (false negative) of ischaemia at DSE in the same vascular territories. Similarly, in absence of significant stenosis, none of these indices was significantly different in the presence (false positive) or absence (true negative) of regional ischaemia (figs 2-4). However, there was a trend to higher dyssynergy index in both true and false positive studies (fig 3 ) and a trend to a higher akinetic-dyskinesis index in the false negative studies (fig 4).

\section{Discussion}

The assessment of the extent of coronary artery disease and residual myocardial ischaemia is important for prognostic stratification of patients after myocardial infarction. ${ }^{1}$ Exercise stress testing in conjunction with myocardial perfusion scintigraphy is widely used for this purpose. However, exercise performance in these patients may be limited by pulmonary and joint disease, physical deconditioning, and particularly exertional dyspnoea owing to left ventricular dysfunction. DSE may be an alternative method for the functional assessment of coronary disease in these patients. However, few data are available on the usefulness of this technique in the evaluation of the extent of coronary artery disease in patients with myocardial infarction. Furthermore, in the presence of resting WMA, the diagnosis of coronary artery stenosis may be falsely elicited by the tethering effect of dyssynergic segments during stress, which in an adjacent normal segment can mimic ischaemia. Because of these potential limitations, it was suggested that myocardial perfusion scintigraphy was the preferred technique for the diagnosis of ischaemia in patients with resting WMA. ${ }^{5}$

\section{THE PRESENT STUDY}

Our study shows a good overall accuracy of DSE for the diagnosis of significant coronary artery stenosis in symptomatic patients with regional left ventricular dysfunction after myocardial infarction, based on the detection of inducible ischaemia. Sensitivity was higher in multivessel disease than in single vessel disease, which can be explained by a larger amount of jeopardised myocardium. The high sensitivity in multivessel disease is an advantage of the technique, because these patients were shown to have a worse prognosis. ${ }^{12}$ 


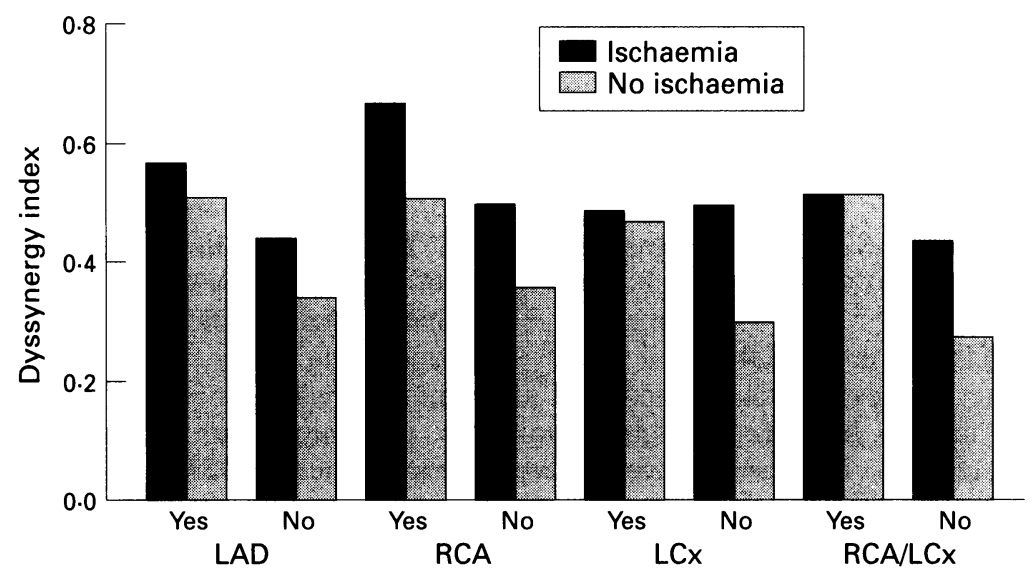

Figure 3 Regional dyssynergy index in individual vascular territories with or without significant stenosis of the related artery and in the presence or absence of regional ischaemia during dobutamine stress echocardiography.

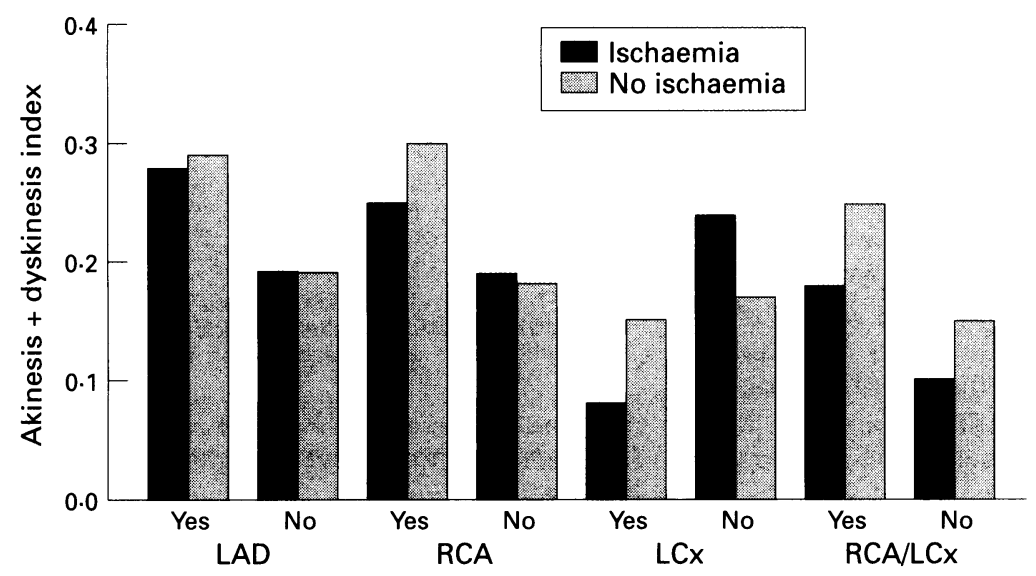

Figure 4 Regional akinesis + dyskinesis index in individual vascular territories with or without significant stenosis of the related artery and in the presence or absence of regional ischaemia during dobutamine stress echocardiography. criteria for the diagnosis of ischaemia in akinetic and dyskinetic segments are lacking, but such segments are not usually found throughout the entire vascular territory. Finally, ischaemia can be detected in hypokinetic segments when akinesis or dyskinesis occur during stress. WMSI, which is an overall estimate of the extent and severity of baseline dysfunction, did not influence the stress results in the presence or absence of significant stenosis. This was demonstrated by the similar WMSI in true positive compared with false negative and in true negative compared with false positive results. However, there was a constant trend for the percentage of dyssynergic segments to be higher in association with both true and false positive results. This may be explained by a the possible confounding effect of tethering in presence of extensive WMA which may passively increase sensitivity by reducing specificity. We also found a constant trend for the number of akinetic and dyskinetic segments to be higher in false negative than in true positive results. However, the difference was small and did not reach a statistical significance.

\section{COMPARISON WITH PREVIOUS STUDIES}

This is the first study to evaluate the accuracy of DSE in the detection of coronary artery stenosis in a homogeneous population of patients with old myocardial infarction. Berthe et al reported a sensitivity of DSE of $85 \%$ and a specificity of $88 \%$ for the diagnosis of multivessel disease in 30 patients after a recent myocardial infarction. ${ }^{2}$ Takeuchi et al reported a sensitivity and specificity of $93 \%$ and $91 \%$ of DSE for the detection of significant infarct related artery stenosis after a recent myocardial infarction. ${ }^{3}$ Sawada et $a l^{4}$ reported that in 41 patients with resting WMA, the sensitivity and specificity of DSE for the detection of coronary artery disease in remote segments were $81 \%$ and $87 \%$ respectively. However, none of theses studies assessed both remote and peri-infarction ischaemia and there are no reports concerning the overall accuracy in patients with resting WMA. Marcovitz et al reported that in a heterogeneous patient population with or without baseline WMA undergoing DSE, most of the false positive results were encountered in patients with baseline WMA. ${ }^{6}$ Conversely, Armstrong et al reported a trend for a higher accuracy in patients with than without baseline WMA undergoing exercise echocardiography. ${ }^{7}$ However, these two studies considered the diagnosis of coronary artery stenosis in presence of baseline WMA that did not change during stress. The contradiction may be explained by a difference in the proportion of patients with resting WMA who had no significant stenosis of the infarct related artery, as occurs after thrombolysis or revascularisation procedures. WMA with causes other than coronary artery disease will further compromise the specificity of this approach which has also the limitation of failure to disclose the relation between the patients' symptoms and inducible ischaemia.

The sensitivity and specificity of DSE for regions. The finding of more severe coronary stenosis in arteries when there was WMA in the related territories may enhance sensitivity in dyssynergic territories. Echocardiographic 
the diagnosis of overall or remote coronary artery stenosis in patients with old infarction in our study accord with those found in other studies in population without previous myocardial infarction ${ }^{11}$ and in heterogeneous populations. ${ }^{4616}$

\section{ACCURACY FOR INDIVIDUAL CORONARY ARTERY DISEASE}

There was no significant difference in the sensitivity for detecting coronary stenosis in the three territories. A similar finding has been reported by Marwick et al. ${ }^{1}$ In contrast, Armstrong et al found a lower sensitivity of exercise echocardiography for LCx. ${ }^{7}$ This may be related to the post exercise acquisition of images and interference on the lateral wall from respiratory movement. In our study, the assignment of the inferior wall to the RCA and posterior wall to the $\mathrm{LCx}$ was associated with a relatively low sensitivity for LCx disease and a low specificity for RCA. This can be explained by the vascular overlap described by other investigators. ${ }^{7}$ When the RCA and LCx were considered together, specificity increased only for the RCA and was slightly reduced for the LCx, suggesting that a significant proportion of inferior ischaemia was caused by LCx disease, meanwhile a relation between posterior ischaemia and RCA disease may not be as significant.

\section{LIMITATIONS OF THE STUDY}

Most patients were receiving medications, including $\beta$ blockers in $29 \%$, which may reduce the sensitivity of DSE. However, we have previously shown that atropine increases the sensitivity of dobutamine echocardiography especially in patients receiving $\beta$ blockers. ${ }^{8}$ Not many patients were without significant coronary artery disease. This is expected in symptomatic populations after myocardial infarction. Therefore we performed the analysis on a segmental basis to avoid this limitation, which is related to the nature of the study population. Myocardial ischaemia detected during DSE was used to predict the presence or absence of significant coronary artery stenosis. However, there may be a discrepancy between coronary anatomical and functional abnormalities. This may explain in part some of the false positive and false negative results at DSE when the test is correlated with angiographic findings as a reference standard. The prognostic value of a positive DSE in patients with myocardial infarction requires further assessment. Preliminary reports indicate that after an uncomplicated infarction, a positive DSE recognises a subset of patients at high risk of adverse cardiac events. In patients with positive DSE, but not in those with a negative DSE, revascularisation dramatically reduced the incidence of cardiac events. ${ }^{17}$ These data suggested that the natural course can be profoundly changed by interventions targeted according to the results of physiological testing. However, many large studies are required to assess the independent or the complementary prognostic significance of the findings at DSE and those obtained by coronary angiography.

\section{SUMMARY AND CONCLUSION}

Our results are derived from a consecutive series of symptomatic patients with previous myocardial infarction referred for non-invasive evaluation of coronary artery disease and showing a wide range of baseline left ventricular dysfunction. The theoretical limitation of echocardiographic detection of ischaemia in presence of baseline dyssynergy did not hold in our study. Conversely, the presence of mild or moderate abnormalities was associated with a higher sensitivity compared with normal or severely dyssynergic segments. DSE is an accurate method for the detection of functionally significant coronary artery disease in patients with myocardial infarction. In this population, the presence of baseline dyssynergy should be disregarded as a limitation of the test for the diagnosis of significant coronary artery stenosis on basis of inducible ischaemia.

A E is supported by the Department of Cardiology, Cairo University Hospital, Cairo, Egypt. M L G is supported by the Dutch Heart Foundation (grant NHS 94.135).

1 Brown KA, Weiss RM, Clements JP, Wackers FJTh. Usefulness of residual ischemic myocardium within prior infarct zone for identifying patients at high risk late after acute zone for identifying patients at high risk late after
myocardial infarction. Am 7 Cardiol 1987;60:15-9.

2 Berthe C, Pierard LA, Hiernaux M, Trotteur G, Lempereur P, Carlier J, et al. Predicting the extent and location of coronary artery disease in acute myocardial infarction by nary artery disease in acute myocardial infarction by echocardiography during

3 Takeuchi M, Araki M, Nakshima Y, Kuroiwa A. The detection of residual ischemia and stenosis in patients with acute myocardial infarction with dobutamine stress echocardiography. F Am Soc Echocardiog 1994;7:242-52.

4 Sawada SG, Segar DS, Ryan T, Brown SE, Dohan AM, Williams R, et al. Echocardiographic detection of coronary artery disease during dobutamine infusion. Circulation 1991;83:1605-14

5 Marwick TH. Stress echocardiography: Its role in the diagnosis and evaluation of coronary artery disease. Dordrecht/ Boston/London: Kluwer, 1994;131.

6 Marcovitz PA, Armstrong WF. Accuracy of dobutamine stress echocardiography in detecting coronary artery disease. Am $\mathcal{F}$ Cardiol 1992;69:1269-73.

7 Armstrong WF, O'Donnell J, Rayan T, Feigenbaum $\mathrm{H}$. Effect of prior myocardial infarction and extent and location of coronary artery disease on accuracy of exercise echocardiography. $\mathcal{F} \mathrm{Am}$ Coll Cardiol 1987;10:531-8.

8 Fioretti PM, Poldermans D, Salustri A, Forster T, Belloti E, Boersma E, et al. Atropine increases the accuracy of dobutBoersma E, et al. Atropine increases the accuracy of dobut-
amine stress echocardiography in patients taking betablockers. Eur Heart $\mathcal{f}$ 1994;15:355-60.

9 Arnese M, Fioretti PM, Cornel JH, Postma-Tjoa J, Reijs AEM, Roelandt JRTC. Akinesis becoming dyskinesis during high-dose dobutamine stress echocardiography: a marker of myocardial ischemia or a mechanical phenomenon? $A m \mathcal{F}$ Cardiol 1994;73:896-8.

10 Baptista J, Arnese M, Roelandt JRTC, Fioretti P, Keane D, Escaned $\mathrm{J}$, et al. Quantitative coronary angiography in the estimation of the functional significance of coronary stenosis: correlation with dobutamine-atropine stress test. $\mathcal{f} \mathrm{Am}$ Coll Cardiol 1994;23:1434-9.

11 Marwick TH, D'Hondt AM, Baudhuin T, Willemat A, Wijns $\mathrm{W}$, Detry J, et al. Optimal use of dobutamine stress for the detection and evaluation of coronary artery disease: combination with echocardiography, scintigraphy or both? $\mathcal{f} \mathrm{Am}$ Coll Cardiol 1993;22:159-67.

2 Proudfit WJ, Bruschke AVG, MacMillan JP, Williams GW. Sones FM. Fifteen year survival study of patients with obstructive coronary artery disease. Circulation 1983;68: 986-97.

13 Andre-Fouet X, Pillot M, Leizorovicz A, Finet G, Gayet C, Milan H. "Non-Q wave," alias "nontransmural," myocardial infarction a specific entity. Am Heart $f$ 1989;117: 892-902.

14 Coma-Canella I, Gomes Martinez MV, Rodrigo F, Castro Beiras JM. The dobutamine stress test with thallium-201 Bingle-photon emission computed tomography radionuclide angion: postinfarction study. $7 \mathrm{Am}$ Coll Cardiol 1993;22:399-406.

15 Braunwald E, Kloner RA. The stunned myocardium: prolonged, postischemic ventricular dysfunction. Circulation 1982;66:1146-9.

16 Dagianti A, Penco M, Agati L, Sciomer S, Dagianti A, Rosanio S, et al. Stress echocardiography: comparison of predicting the extent of coronary artery disease. $\mathcal{F} \mathrm{Am}$ Coll Cardiol 1995;62:18-25.

17 Bigi R, Landi P, Pingitore A, Heyman J, Mattioli R, Seveso $\mathrm{G}$, et al. The prognostic value of dobutamine-atropine stress echocardiography early after acute 